\title{
EL POEMA EN PROSA SILESIANO COMO UN PALIMPSESTO MÉTRICO
}

\author{
THE SILES' PROSE POEM AS A \\ METRICAL PALIMPSEST
}

\author{
HENRY GIL \\ Universidad de París Este Marne-la-Vallée, LISAA EA-2140
}

Resumen: Este artículo trata de mostrar cómo algunos poemas juveniles de Jaime Siles aparentemente en prosa disimulan en realidad una estructura métrica clásica. Es tanto más interesante cuanto que estos metros enmascarados por la prosa han de desempeñar una función semántica en relación con el contenido del poema. Por otra parte, estos poemas en prosa que, en realidad, no son más que palimpsestos métricos, parecen anunciar ya, a pesar de manifestarse en el período de los años setenta del siglo pasado, dominado en gran parte, en España, por formas libres, determinadas estructuras clásicas reactivadas y luego desarrolladas en la obra posterior de Jaime Siles.

Palabras clave: poema en prosa, palimpsesto métrico, versos enmascarados, «Hemisferio», silva, heptasílabos y endecasílabos, alejandrinos.

Abstract: This article aims to show how some of Jaime Siles's early poems, seemingly prose poems, actually follow a conventional metrical pattern. This is all the more interesting as those meters, masked by prose, play a semantic role in direct link with the content of the poem. Besides, those prose poems, which are in fact nothing but metrical palimpsests, even though they were written in the 1970s -an era largely dominated in Spain by free 
forms- seem to herald some of the renewed classical structures Jaime Siles further develop in his later works.

Key words: prose poem, metrical palimpsest, masked verse, «Hemisphere», silva, heptasyllables and hendecasyllables, alexandrines. 


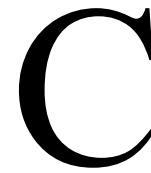

uando Paul Valéry, poeta tan mediterráneo como Jaime Siles, define, en Tel quel, la poesía como «esta prolongada vacilación entre el sonido y el sentido ${ }^{1} »$, no sólo insiste en el aspecto voluntaria y aparentemente ambiguo de la poesía, necesario tanto para acceder a una nueva y original expresión como para garantizar su polisemia, sino que afirma tajantemente la indisolubilidad existente dentro del lenguaje poético entre el sonido y el significado. Esta indisolubilidad entre el sonido y el sentido que hace que un texto poético constituye siempre un pequeño enigma y un verdadero reto para quien decide ser su traductor, es lo que permite dar paso a la significidad, la cual no es sino, para mí, el trabajo polisémico del significante. De ahí una voz poemática que huye deliberadamente de lo que Mallarmé llamaba «el lenguaje del universal repor$\operatorname{taje}^{2} \gg$, ese lenguaje cotidiano, prosaico y utilitarista. Ahora bien, cuando Valéry habla de «sonido», hemos de pensar no sólo en el significante sonoro con todas sus potencialidades (aliteraciones, asonancias y paronomasias) sino también en su estructuración prosódica y con ella en su ritmo que esté o no asociado a un sistema métrico en el que se funda el poema.

Entre los poetas españoles que siguen escribiendo hoy en día con versos clásicos o tradicionales y no con este verso libre que, con humor Jacques Roubaud llama el VIL -el gran Verso

$\overline{1}$ «Le poème -cette hésitation prolongée entre le son et le sens». VALERY, Paul: Tel quel, folio essais. París: Gallimard, 2008, p. 265.

${ }^{2}$ Mallarme, Stéphane: «Crise de vers», en Divagations, Euvres Complètes, t.II. Paris: Gallimard, Bibliothèque de la Pléiade, 2003, p. 212. En 1877, cuando escribió esto Mallarmé, la palabra «reportage» en francés, se veía aún como un anglicismo, de ahí el uso de la cursiva, que alude, aquí, de modo muy despectivo a cierto periodismo ajeno a los artículos de fondo o las grandes crónicas y que remite a los simples y vulgares sucesos sin trascendencia. Para Mallarmé, el lenguaje del universal reportaje se opone radicalmente al lenguaje poético. 
Internacional Libre ${ }^{3}$, Jaime Siles, gran conocedor de la poesía española, tanto de la barroca como de la moderna o contemporánea así como de las poesías grecolatinas y de múltiples poéticas extranjeras, es probablemente uno de los mejores versificadores actuales en lengua española. Durante un poco más de cuarenta años de creación poética, Jaime Siles supo utilizar las formas codificadas más variadas de la poesía española -soneto, silva, endecha, décima, romance, lira castellana, cosaute, seguidilla-, lo cual no le impidió nunca crear sus propias formas poéticas y valerse a veces de una gran polimetría que puede dar a pensar a muchos que ciertas composiciones están escritas en versos libres cuando abundan en casi todas éstas los versos cultos, heptasílabos, endecasílabos y alejandrinos. y nunca de manera gratuita. Muchas veces la polimetría de ciertos poemas silesianos por la frecuencia con la que se repiten los versos que acabamos de citar se asemeja en realidad a variantes de la silva, esta forma que por ser codificada no deja de ser bastante libre puesto que la combinación es totalmente asimétrica, o sea libre como las disposiciones de sus rimas cuando no se trata de lo que se llama precisamente una silva libre, la cual prescinde entonces de toda rima. Pero, en la poesía de Jaime Siles, la forma, cualquiera que sea, participa siempre de manera muy activa en la significación del poema. Pues siempre ha habido en su obra una gran y muy sutil adecuación entre las formas poéticas utilizadas y el significado de los textos poéticos que éstas elaboran ${ }^{4}$.

${ }^{3}$ Para Jacques Roubaud, como lo explica él en Poésie, etcetera: ménage (París: Stock, 1995, p. 153), el VIL, este gran Verso Internacional Libre es un verso libre estándar que se contenta con ir a la línea y que se ha impuesto en muchos países. El VIL se produce, según Roubaud, cuando «les conditions formelles d'une poésie sont molles et floues», p. 153. Para Roubaud, poeta oulipiano que adopta una reacción voluntariamente antivanguardista y anti rupturista sin dejar, por ello, de situarse en una modernidad fuertemente inventiva, estas «condiciones formales blandas y borrosas» se olvidan de que la poesía es memoria y memoria de una lengua, de la cual forman parte los versos clásicos.

${ }^{4}$ Todo esto queda muy claro en su obra -como traté de mostrarlo en un largo estudio titulado Langage, ontologie et esthétique dans la poésie de Jaime Siles (19691999), que se publicará próximamente en ENS Éditions- según opte el poeta por formas epigrámaticas destinadas a expresar la esencia, breves poemas en los que hay una erradicación o contención del Yo y una omnipresencia del presente o formas elegíacas largas, a menudo discursivas y meditativas, con varios tiempos verbales que coinciden con la expresión de un Yo explícito, destinado a expresar 
Es así como lo demostraba ya su famoso poema «Tragedia de los caballos $\operatorname{locos}^{5} \gg$, escrito a los diecisiete años. Por eso el verdadero fresco sensorial que es este poema adolescente se construye principal y significativamente en la primera parte -durante la cabalgata loca de estos caballos- a partir de alejandrinos escalonados, que, en la segunda parte -cuando se produce el progresivo encuentro con las yeguas con las que van a acoplarse para morir después-, tienden a alargarse hasta transformarse, o mejor dicho diluirse, en versículos de más de veinte sílabas, dispuestos ya de manera seguida en los últimos versos del poema. En este poema muy aleixandrino por la temática de «el amor y la destrucción» que lo preside, el paso del ritmo muy marcado del alejandrino a otro aún más amplio e irregular -el de los largos versículos- da fe de la fusión casi cataclísmica de estos caballos -cuyo galope parece proceder del propio cuerpo de un Yo, de su oído y quizá de su propio ritmo sanguíneo- con el cosmos. Un Yo que, a través de su facultad auditiva, sólo se manifiesta puntualmente al principio:

Dentro de los oídos, ametralladamente

Escucho los tendidos galopes de caballos

y al final del poema :

y súbito, como en una caracola fenecida, en los oídos escucho un desplomarse patas rabiosas, una nube de polvo levantado por crines

Es así como en Siles el ritmo métrico no sólo vertebra la composición sino que suele participar activamente en su significado. $\mathrm{Y}$ es lo que vamos a tratar de demostrar, ahora, con dos poemas silesianos, uno sacado de Génesis de la luz (1969), titulado «Hemisferio»y otro que no lleva título pero que abre Canon

el dolor existencial. La forma poética, se trate de una micro-estructura (el verso) o una macro-estructura (el poema), se ajusta siempre muy acertadamente a los significados e intenciones de la voz poemática silesiana.

${ }^{5}$ Canon (1969-1973), en Poesía 1969-1990. Madrid: Visor de Poesía, 1992, pp. 5051. En realidad, cabe recordar que anteriormente este poema apareció en Génesis de la luz, El Guadalhorce, 1969. 
(1969-1973). Dos poemas que pertenecen a los principios de la obra silesiana y que paradójicamente tienen la singularidad de presentarse, desde un punto de vista tipográfico, como textos en prosa. Y dos poemas además en gran parte metapoéticos como lo veremos y que parecen, en realidad, haber sido elaborados métricamente a pesar de su presentación prosificada, pero en los que esta métrica subyacente, no perceptible desde un punto de vista tipográfico, está, sin embargo, cargada de significados y aún más en su versión en prosa.

Un rápido vistazo sobre Génesis de la luz podría dar a pensar que su temprana escritura pudiera sugerir una total despreocupación por las formas tradicionales y su métrica correspondiente, como en el caso de varios poemas novísimos y, por lo general, de una buena parte de la poesía castellana de los años setenta ${ }^{6}$. $\mathrm{Y}$ en efecto, cabe notar que la mayor parte de los poemas de este primer poemario lleva versos a veces muy largos, de unas veinte sílabas. De modo que la impresión que domina es la de poemas monolíticos de unos veinte versos, con frases muy largas que superan frecuentemente el marco métrico clásico ya que la sintaxis es trabajada casi sistemáticamente aquí por la amplificación como en el poema epónimo «Génesis de la luz ${ }^{7}$ », donde se acumulan las oraciones relativas y las enumeraciones interminables. Además encontramos, en este libro, tres poemas en prosa que son «Edgar Allan Poe», «No» y «Hemisferio». Si los dos primeros poemas pueden relacionarse puntualmente con ciertos metros (hexasílabos, alejandrinos y endecasílabos) a los que parecen remitir ciertas frases, «Hemisferio» nos aparece, en cambio, si prestamos atención a su ritmo, como una auténtica silva prosificada compuesta principalmente de heptasílabos y de algunos endecasílabos y pentasílabos ${ }^{8}$. Pero, veamos primero como se presenta este poema en prosa en el poemario:

${ }^{6}$ Estas tendencias no impiden, por supuesto, notables excepciones como la «Oda a Venecia ante el mar de los teatros» de Pere Gimferrer, escrita en alejandrinos o distintos poemas de Antonio Carvajal que escribe varios sonetos regulares.

${ }^{7}$ Génesis de la luz (1969), Poesía (1969-1990), cit., p. 15.

${ }^{8}$ José Enrique Martínez señala también la presencia de «una sucesión de heptasílabos y endecasílabos enmascarados» en algunos poemas supuestamente en prosa de Génesis de la luz y Canon, en «Los juegos de la rima en un poema de Jaime Siles», Rhythmica. Revista española de métrica comparada, Sevilla, 2010, VIII, 8, p. 102. 
HEMISFERIO 9

Este ir y venir por los rincones de un cuerpo sin fronteras es de las miradas frías.

[recorrer el hemisferio oculto En las manos más hondas de un verano sin luna el horizonte tiembla.

Cuanto mis ojos vieron bajo la llama del silencio blanco, tus pies lo [empujan hacia las playas muertas. Queda el perfil de una caricia, un cabello extraviado [latiendo en la penumbra, el fuego de unos labios de acero, la presencia real que Toda la contingencia azul de corazones.

[abraza el suelo duro.

La silva es, en efecto, como ya se sabe, un poema no necesariamente rimado que combina libremente endecasílabos y heptasílabos sobre una extensión no determinada, y a los cuales pueden añadirse puntualmente versos más cortos pero de ritmo parecido (trisílabos, pentasílabos o eneasílabos). Ahora bien, si tratamos de versificar este poema en prosa, obtenemos 20 versos repartidos del modo siguiente:

\begin{tabular}{|c|c|}
\hline v1 & Es/te// ir/ y/ ve/nir/ por/los/ rin/co/nes \\
\hline v2 & $\begin{array}{l}\text { deun/ cuer/po/ sin/ fron/te/ras } \\
\text { (heptasílabo) }\end{array}$ \\
\hline v3 & $\begin{array}{l}\text { es/ re/co/rrer/ el/ he/mis/fe/rioo/cul/to } \\
\text { (endecasílabo a minore sáfico: } 1.4 .8 .10 \text { ) }\end{array}$ \\
\hline v4 & $\begin{array}{l}\mathrm{de} / \mathrm{las} / \mathrm{mi} / \mathrm{ra} / \mathrm{das} / \text { frílas } \\
\text { (heptasílabo) }\end{array}$ \\
\hline v5 & $\begin{array}{l}\text { En/ las/ ma/nos/ más/ hon/das } \\
\text { (heptasílabo) }\end{array}$ \\
\hline v6 & $\begin{array}{c}\mathrm{deun} / \mathrm{ve} / \mathrm{ra} / \mathrm{no} / \mathrm{sin} / l u / \mathrm{na} \\
\text { (heptasílabo) }\end{array}$ \\
\hline v7 & $\begin{array}{c}\mathrm{el} / \mathrm{ho} / \mathrm{ri} / \mathrm{zon} / \mathrm{te} / \mathrm{tiem} / \mathrm{bla} \\
\text { (heptasílabo) }\end{array}$ \\
\hline v8 & $\begin{array}{c}\text { Cuan/to/ mis/ o/jos/ vie/ron } \\
\text { (heptasílabo) }\end{array}$ \\
\hline v9 & $\begin{array}{l}\mathrm{ba} / \mathrm{jo} / \mathrm{la} / \text { lla } / \mathrm{ma} / \mathrm{del} / \mathrm{si} / \text { len } / \mathrm{cio} / \text { blan } / \mathrm{co} \\
\text { (endecasílabo a minore sáfico: } 4.8 .10)\end{array}$ \\
\hline v10 & $\begin{array}{l}\text { tus/ pies/ loem/pu/jan } \\
\quad \text { (pentasílabo) }\end{array}$ \\
\hline
\end{tabular}

${ }^{9}$ Génesis de la luz (1969), in Poesía 1969-1990, cit., p. 22. 


\begin{tabular}{|c|c|}
\hline v11 & $\begin{array}{c}\text { ha/cia/ las/ pla/yas/ muer/tas. } \\
\text { (heptasílabo) }\end{array}$ \\
\hline v12 & $\begin{array}{l}\text { Que/dael/per/fil } \\
\text { (pentasílabo) }\end{array}$ \\
\hline v13 & 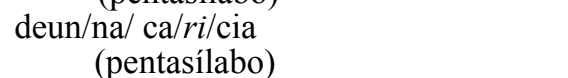 \\
\hline v14 & $\begin{array}{l}\text { un/ ca/be/lloex/tra/via/do } \\
\text { (heptasílabo) }\end{array}$ \\
\hline v15 & $\begin{array}{c}\text { la/ tien/doen/ la/ pe } / \text { num } / \text { bra } \\
\text { (heptasílabo) }\end{array}$ \\
\hline v16 & $\begin{array}{c}\mathrm{el} / \text { fue/go/ deu/nos/ la/bios/ de// a/ce/ro } \\
\text { (endecasílabo heroico: } 2.6 .10 \text { ) }\end{array}$ \\
\hline v17 & $\begin{array}{c}\mathrm{la} / \mathrm{pre} / \mathrm{sen} / \mathrm{cia} / \mathrm{re} / \mathrm{al} \\
\text { (heptasilabo) }\end{array}$ \\
\hline v18 & $\begin{array}{c}\text { quea/bra/zael/ sue/lo/ dura } \\
\text { (heptasílabo) }\end{array}$ \\
\hline v19 & $\begin{array}{l}\text { to/da/ la/ con/tin/gen/cia } \\
\text { (heptasílabo) }\end{array}$ \\
\hline v20 & $\begin{array}{l}\mathrm{a} / \mathrm{zul} / \mathrm{de} / \mathrm{co} / \mathrm{ra} / z o / \mathrm{nes} \\
\text { (heptasílabo) }\end{array}$ \\
\hline
\end{tabular}

Podemos observar que este poema, cuando lo versificamos, consta pues de 13 heptasílabos, de 4 endecasílabos y 3 pentasílabos mezclados libremente, lo cual lo asemeja perfectamente a una silva. Sin embargo, Jaime Siles decidió que este texto apareciera en su poemario no en una forma versificada sino prosificada. Por lo tanto, esta decisión permite que se establezca un juego muy sutil y algo oculto en el poema entre prosa y verso y que tiene que ver, como voy a tratar de demostrarlo, con un asunto metapoético. En efecto, este poema es a su modo metapoético porque describe de manera metafórica, al menos eso me parece, la búsqueda de un Yo que se escribe mientras habla de su escritura sobre el modo de una identificación entre espacio cósmico y espacio paginal. A través de este poema aparentemente en prosa, la voz poemática evoca pues su búsqueda, su propio itinerario, que al mismo tiempo es su propio ritmo, anunciado desde el principio y designado como Este ir y venir, ya que el deíctico Este se refiere a un Yo implícito que sólo se hace explícito en el segundo párrafo o estrofa con la sinécdoque mis ojos. Un ritmo descrito, a pesar de la prosa, como un verso ya que etimológicamente versus designa un movimiento de retorno (vertere $=$ girar) y por lo tanto de «ir y venir». Detrás 
o mejor dicho en el seno mismo de la aparente linealidad de la prosa-prorsus sugiere un movimiento que va hacia delante, todo recto, «que anda en línea recta- se perfila pues un hemisferio oculto que es el del verso, el de una línea que gira, que va en un sentido y luego antes de llegar al final vuelve y parece, gracias a la mirada del que escribe o lee, desandar lo andado, un movimiento pues de «ir y venir» acompasado con fenómenos recurrentes y variables, propios de una escritura versal. Quizá encontremos con la sinestesia silencio blanco, algo que se creía consumido (llama del silencio blanco) o perdido, pero cuyo ritmo permanece en la penumbra bajo una forma ínfima, la de un cabello extraviado latiendo en la penumbra, un poco como el ritmo de estos dos heptasílabos que pueden también leerse como un alejandrino o el de los demás versos prosificados -endecasílabos, heptasílabos o pentasílabos-, disimulados así en la prosa.

En el segundo párrafo, parece haber un verdadero juego entre dos pronombres personales, referidos ambos, yo creo, a la voz poemática, tanto el Yo como el Tú se refieren siempre al sujeto hablante y no a veces a un ser amado como podría dejarlo suponer el pronombre de segunda persona. Dado que el Tú corresponde aquí a una especie de testaferro que no es sino el propio Yo, duplicado en tú. De modo que cuando la voz poemática habla en segunda persona no sólo lo hace para la alocución a otro sino a sí misma. Por eso, cuanto mis ojos vieron corresponde, me parece, a un Yo que se refiere a su experiencia pasada como lo indica el pretérito y luego el Tú: tus pies lo empujan hacia las playas muertas, puede remitir, él también, al Yo, pero a un Yo desdoblado y que entonces se dirige a sí mismo ya que medita ahora sobre su acción presente como lo indica el cambio de tiempo verbal, la de la escritura poética ya que la imagen de pies conlleva la de pasos como metáfora de la escritura. Además el término pies conviene tanto para la marcha, la que ocupa o explora un espacio constantemente sugerido aquí por toda una isotopía (hemisferio, ir y venir, rincones, fronteras, playas, suelo), como para una unidad de medida relacionada con el verso, aquí subyacente. Todo lo que registró la mirada del Yo, en su experiencia pasada, se ve transportado ahora por un Tú -que no es sino el Yo que medita sobre sí mismo- hacia playas muertas. Unas «playas» que son 
como una nueva imagen de la página, este espacio plano, vacío, y desierto al que ya no va el mar. A no ser que ahora las olas sean el flujo ritmado de los versos disimulados. Por eso, las frases-versos que siguen, dicen que sobre esas playas muertas subsiste algo: queda un perfil, un cabello extraviado, el fuego de unos labios de acero, la presencia real que abraza el suelo duro, toda la contingencia azul de corazones. Toda una serie de palabras que remiten al campo léxico del amor aunque no creo que haya aquí forzosamente la presencia implícita de un ser amado. Las imágenes del cuerpo sólo sirven para referirse al cosmos y el amor es lo que existe entre éste y el Yo. Se nos habla de una simple huella que, siguiendo un proceso de gradación ascendente, se vuelve cada vez más presente y real (presencia). El título «Hemisferio» remite pues a un mundo, concebido como bipolaridad que connota la imagen de una esfera compuesta de dos hemisferios y en la que la experiencia poética sería la exploración de un hemisferio oculto, pero vinculado al otro, que es el que nos toca vivir todos los días. Hábilmente disimulados en medio de este lenguaje cotidiano por excelencia que es la prosa, los versos crean una métrica subyacente, portadora de un ritmo encargado de notificar la experiencia poética, ofreciendo a quien sabe escucharlo una especie de silva discreta y pregnante a la vez.

Canon (1973), el tercer poemario de Jaime Siles, es un libro clave en la medida en que no sólo recupera los principales aspectos de los poemarios anteriores -búsqueda ontológica, dimensión cósmica, contención del Yo y desde Biografía sola, forma epigramática- sino que con intención de profundizar aún más va a dar con lo que ha de constituir el concepto silesiano sobre el que va a desarrollarse buena parte de la obra, el del universo y de la nada como elementos sonoros:

Todo es música, nota, diapasón

Hasta los cuerpos en la nada suenan ${ }^{10}$.

(«Daimon Atopon»)

Es así como la nada sonora aparece como el postulado que se vuelve fuente de todos los signos que rodean al Yo y hasta lo

${ }_{10}$ «Daimon Atopon», Canon (1969-1973), en Poesía (1969-1990), cit., p. 49. 
constituyen. Canon, como lo indica su título musical, se propone reproducir el eco fiel de su voz originaria. De ahí la exhortación del locutor silesiano, destinada a restituirnos esta voz primitiva en «Espacio último» -poema que consta de 14 epigramas-: $R e$ troceda a su voz también el eco. Gracias a su polifonía, Canon nos permite pasar de la unidad a la multiplicidad del ser como lo sugería ya la poética silesiana de 1974 .

El libro se abre con un epígrafe que es una definición del término «canon» sacado de un Diccionario de retórica: «Canon: forma de escritura contrapuntística cuyas partes entran sucesivamente y en la que cada una repite la misma figura melódica o rítmica que la primera voz. ${ }^{11} \gg$ Siles nos propone valerse de una forma de escritura contrapuntística que ha de permitir una visión dialéctica del ser que no es sino una lucha entre el ser y el no ser como queda manifiesto con el uso constante de isotopías : la del sonido (voz, eco, murmullo, música, sonido, silencio...), la de la luz (claridad, destello, fuego, rayo, sombra...), la del tiempo (tiempo, sucesión, duración, permanencia, instante, eternidad...) mientras que dominan las dos isotopías primordiales a las que las demás están todas supeditadas y que son las del ser (ser, esencia, identidad, plenitud...) y del no ser (nada, vacío, hueco, olvido, negación, noche) sin contar las modulaciones negativas del sonido y de la luz que son el silencio y la sombra.

Esta vez el poema en prosa ${ }^{12}$-el único en todo en el poemario- es un texto inaugural ya que abre el libro como si se tratara de una especie de preámbulo cuyo papel proemial parece aquí sugerido por la ausencia misma de título referido a este texto. Sin embargo, se trata de un poema introducido, a su vez, muy sutilmente por este epígrafe de Ovidio: «... erutaque ex imis fervet harena fretis» que significa «... la arena del fondo del oleaje se anima», un epígrafe que no está sin relacionarse con el procedimiento llevado a cabo en el texto que es el siguiente:

Mis labios llegan a la playa más alta, a la arena más honda, a besar esos átomos sin espacio, del aire. Beben la espuma herida por cuerpos temblorosos, acarician las noches de estaño o laterita, modulan tibiamente el perfil de las voces, las palabras sin rostro de las luces oscuras.

${ }^{11}$ Ibid., p. 39.

${ }^{12}$ Ibid., p. 45. 
Hay un túnel de sombra más allá de los ojos. Y un hilo verde dice que la memoria existe. Es la retina viva que vibra en la garganta, el oleaje eterno que desconoce límites, el caballo sin freno que la muerte detiene.

Cabe notar de entrada que en este poema también encontramos de nuevo el cuerpo cósmico o mejor dicho una comunión carnal entre el cuerpo del Yo y el cosmos. Comunión que es amor (besar), fuente de vida (beben) y canto o expresión poética (modulan el perfil de las voces), expresados como celebración hiperbólica del ser, como lo indican los superlativos: más... más y las palabras que connotan la intensidad: alta, honda, átomos.

Pero lo más interesante es ver cómo existe también aquí, en este poema supuestamente en prosa, una estructura métrica subyacente, bastante perceptible para quien decide escuchar su ritmo, en gran parte vinculado a la sintaxis del texto, estructura métrica particularmente rica en significados. La versificación de este segundo poema en prosa da lo siguiente:

$\begin{array}{ll}\text { v } 1 & \text { Mis labios llegan } \\ \text { v } 2 & \text { a la playa más alta, a la arena más honda, } \\ \text { V } 3 & \text { a besar esos átomos, sin espacio, del aire. } \\ \text { V } 4 & \text { Beben la espuma herida por cuerpos temblorosos } \\ \text { v } 5 & \text { acarician las noches de estaño o laterita, } \\ \text { v } 6 & \text { modulan tibiamente el perfil de las voces, } \\ \text { v } 7 & \text { las palabras sin rostro de las luces oscuras. } \\ \text { v } 8 & \text { Hay un túnel de sombra más allá de los ojos. } \\ \text { V } 9 & \text { Y un hilo verde dice que la memoria existe. } \\ \text { V 10 } & \text { Es la retina viva que vibra en la garganta, } \\ \text { V 11 } & \text { el oleaje eterno desconoce límites, } \\ \text { v 12 } & \text { el caballo sin freno que la muerte detiene. }\end{array}$

Es interesante observar que el único sintagma que no da lugar a un heptasílabo que pudiera servir de hemistiquio primero o segundo a un alejandrino, es el que abre el poema: Mis labios llegan, este sintagma pentasilábico podría como mucho asociarse con el sintagma siguiente, que, él, es heptasilábico para dar un dodecasílabo (5/7): Mis labios llegan a la playa más alta. Pero nos parece preferible considerarlo aparte, como un pentasílabo, 
ya que el segundo sintagma se funde, él, muy naturalmente en el molde de un alejandrino, al constituir entonces el primer hemistiquio de un metro que, a partir de ahora, va a repetirse 11 veces sin ninguna interrupción hasta el final del texto. Es así como 11 alejandrinos parecen seguir el primer verso pentasilábico. Además la presencia de un metro diferente para abrir el poema se justifica tanto más cuanto que se trata del único sintagma que encierra al Yo, presentado una vez más en este libro con una sinécdoque: Mis labios, que nos remiten no sólo al beso (besan esos átomos), a la acción vital de beber (beben la espuma), sino también a una acción sensual (acarician) que no es más que el canto de la voz poemática (modulan tibiamente el perfil de las voces). Una vez más la voz se pone pues en escena mostrando cómo gracias a ella se nos revela una armonía secreta, la de los versos disimulados al fondo de la prosa, que nos recuerdan el ritmo, él también, íntimo pero invisible que anima, según Ovidio, la arena que se encuentra al fondo del mar. Esta armonía secreta expresada aquí con alejandrinos enmascarados por la prosa, sólo es posible o mejor dicho perceptible gracias a la presencia, al principio del poema, del sintagma pentasilábico que se refiere al poder de la voz. Es interesante, por cierto, constatar que si el primer párrafo o estrofa corresponde a la voz propiamente dicha, a su expresión, Mis labios, el segundo, él, parece concernir, a través de una sinestesia: la retina viva que vibra en la garganta, a la mirada de esta voz o mejor dicho sugerir el hecho de que ésta, tal un vidente pueda ser visionaria y ver más allá de los ojos y más allá de la muerte, dicho de otro modo oír -la sinestesia es una figura obligada de este texto: el perfil de las voces- otras voces (el oleaje eterno que desconoce límites) que estructuran y ritman sin fin este sistema musical o canon con el cual se abre este libro.

Estos dos poemas en prosa suponen pues, como lo hemos visto, una etapa previa en versos que ha sido, sin embargo, totalmente disimulada al prosificarse dichos textos. Esto puede recordar un poco lo que antiguamente sucedía con algunos antiguos pergaminos donde se borraban ciertos textos para escribir nuevos sobre el mismo soporte dando lugar a lo que llamamos palimpsestos. Sólo que aquí, en estos poemas silesianos, borrar 
consiste en disimular desde un punto de vista tipográfico las líneas versales. De modo que, contrariamente a los verdaderos palimpsestos, lo que se borra no son las palabras sino su segmentación versal pero no su orden sintáctico ni acentual. Así que este orden sintáctico y acentual ha de conservar en un plano sólo virtual para el ojo pero no para el oído el orden métrico. Ya que basta pues con leer correctamente estos poemas para que los versos resuciten y se extraigan de estas masas prosificadas revelando así su ritmo tras la aparente indefinición de la prosa. La idea del palimpsesto es interesante porque parece remitir a la de la memoria. Una idea de memoria de la forma, aquí la forma métrica -los endecasílabos, heptasílabos o alejandrinos enmascarados- que pertenece también como lo diría Jacques Roubaud a la memoria de la lengua. Pues, el verso, como lo explica el mismo Roubaud, es «le lieu par excellence de la mémoire, où la langue, le desir-être de la langue, retourne (versus), et répète... C'est un lieu de mémoire ${ }^{13} \gg$.

Jaime Siles es, por otra parte, un poeta que a menudo vuelve a retocar sus versos, sus poemas y por supuesto sus poemarios para redondearlos y dar por fin con el marco definitivo que mejor les convenga. En un poema como «El oro de los días $\left.{ }^{14}\right\rangle$ escrito con alejandrinos que juegan con rimas asonantes y consonantes, externas e internas ${ }^{15}$, esta forma alejandrina procede probablemente de un poema previo escrito con heptasílabos una de sus formas más empleadas- hasta que dio con el poema definitivo. En este caso la ocurrencia está en el manejo muy sutil del alejandrino que por ser un verso compuesto parece introducir, en este poema fuertemente elegíaco, dos tiempos como pueden serlo temáticamente, por una parte, el pasado de la juventud $\mathrm{y}$, por otra, el presente de la madurez que construye a partir del primero sus recuerdos. Dos tiempos claramente diferenciados pero que unidos forman el poema como los dos hemistiquios

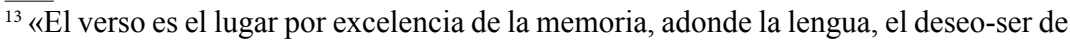
la lengua, vuelve (versus), y repite». Poésie, etcetera: ménage, cit. p. 159.

${ }^{14}$ Himnos tardios. Madrid: Visor de Poesía, 1999, pp. 15-17.

${ }^{15}$ A propósito de «El oro de los días» y de sus juegos sobre las rimas se puede leer el interesante estudio que le dedica José Enrique Martínez, en Rhythmica. Revista de métrica comparada, cit., titulado precisamente «Los juegos de la rima en un poema de Jaime Siles», pp. 95-110. 
independientes del alejandrino se juntan para formar el verso. Un alejandrino que, en este poema, permite subrayar pues este vaivén o «ir y venir», imagen muy recurrente en la poesía silesiana. Y probablemente no es una casualidad si «El oro de los días» termina con un verso heptasilábico «en curso todavía», el único en todo el poema, que debe de recordar el primer esbozo del poema como lo hizo también, a su modo, a partir del verso 41, el primer hemistiquio heptasilábico rimado de este verso «de las que son ruinas». Esta primera rima asonante interna en /í-a/ antes de la cesura va a señalar, a partir de entonces, la posición de la rima para los versos siguientes, una rima asonante ahora interna, subrayada, en el v 41 , por un efecto de diéresis ( $« \mathrm{rü} / \mathbf{i} /$ nas»). En «el oro de los días» es el desplazamiento de la rima del fin del verso al fin del primer hemistiquio lo que nos deja intuir una etapa previa del poema que el texto procura conservar bajo la forma de una huella.

Pero, aquí, en estos dos poemas prosificados del Siles joven, el marco definitivo fue paradójicamente la prosa para obligar al buen lector a que descubriera o al menos a que sintiera él mismo, como frente a un auténtico palimpsesto, el ritmo métrico encubierto aunque no aniquilado. Al principio de nuestro artículo, hemos señalado el parentesco mediterráneo de Siles con Valéry y hemos visto luego como estos dos poemas metapoéticos silesianos se fundan en toda una serie de imágenes marítimas. Nuestro estudio que acaba de poner de manifiesto el vínculo muy estrecho que existe aquí entre la imagen del ritmo marítimo -aludido por el epígrafe de Ovidio que sugiere la animación oculta aunque esencial de «la arena por el fondo del oleaje»-y el ritmo interno ocultado dentro de la prosa pero que ha de intuir el lector, nos muestra de modo indiscutible esta indisolubilidad entre el «sonido» -en su acepción más abierta- y el «sentido», inherente al texto poético, tal como la reivindicaba Paul Valéry. Un ritmo a la vez existencial y esencial puesto que permite sugerir un vínculo muy estrecho entre los seres, cuerpos donde se producen las vibraciones sensoriales de la afectividad, y el Ser, concebido éste a la vez como Cosmos y Logos, o sea como lo Uno-Todo. 
También es interesante observar que, a pesar de haberse escrito en los años setenta del siglo pasado, dominados, en gran parte, por formas aparentemente libres, estos poemas en prosa convertidos en palimpsestos métricos parecen anunciar ya determinadas estructuras luego desarrolladas en la obra posterior del poeta como el uso frecuente de la silva o del poema en alejandrinos. El Siles de los años setenta escribe poemas en prosa que suenan como versos como si quisiera que el propio lector - un lector con buen oído- descubriera al leerlos en voz alta su invisible aunque verdadera prosodia, descubriera o mejor dicho recordara ya que como lo dice Jacques Roubaud, el verso es «un lugar de memoria» que remite a la lengua del poeta y de su lector.

\section{Bibliografía utilizada}

MALLARMÉ, Stéphane: Divagation, en Euvres complètes, tomo II. París: Gallimard, Bibliothèque de la Pléiade, 2003.

MARTÍNEZ, José Enrique: «Los juegos de la rima en un poema de Jaime Siles», Rhythmica. Revista española de métrica comparada. Sevilla, 2010, VIII, 8, pp. 95-110.

ROUBAUD, Jacques: Poésie, etcetera: menaje. París: Stock, 1995.

SILES, Jaime: Poesía 1969-1990. Madrid: Visor de Poesía, 1992.

-Himnos tardios. Madrid: Visor de Poesía, 1999.

VALÉRY, Paul: Tel quel, folio essais. París: Gallimard, 2008. 